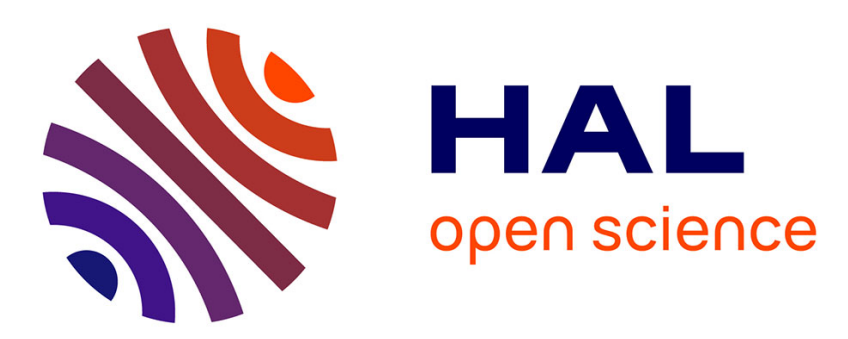

\title{
Assortment decision in the Multi-Product News-Vendor Problem with Demand Substitution
}

Shouyu Ma, Evren Sahin, Yves Dallery, Ziad Jemai

\section{To cite this version:}

Shouyu Ma, Evren Sahin, Yves Dallery, Ziad Jemai. Assortment decision in the Multi-Product News-Vendor Problem with Demand Substitution. IESM Conference, Oct 2015, Sevilla, Spain. hal01260542

\section{HAL Id: hal-01260542 \\ https://hal.science/hal-01260542}

Submitted on 30 Jan 2016

HAL is a multi-disciplinary open access archive for the deposit and dissemination of scientific research documents, whether they are published or not. The documents may come from teaching and research institutions in France or abroad, or from public or private research centers.
L'archive ouverte pluridisciplinaire HAL, est destinée au dépôt et à la diffusion de documents scientifiques de niveau recherche, publiés ou non, émanant des établissements d'enseignement et de recherche français ou étrangers, des laboratoires publics ou privés. 


\title{
Assortment decision in the Multi-Product News-Vendor Problem with Demand Substitution
}

\author{
(presented at the $6^{\text {th }}$ IESM Conference, October 2015, Seville, Spain) (c) $\mathrm{I}^{4} \mathrm{e}^{2} 2015$
}

\author{
Shouyu MA,Evren SAHIN, Yves DALLERY \\ LGI, Centrale Supelec \\ Grande Voie des Vignes \\ 92290, Chatenay Malabry, France
}

Email: shouyu.ma,evren.sahin,yves.dallery@ centralesupelec.fr

\author{
Ziad JEMAI \\ OASIS-ENIT, University of Tunis El Manar \\ BP37 Le Belvedere \\ 1002 Tunis, Tunisia \\ Email: zied.jemai@centralesupelec.fr
}

\begin{abstract}
Retailers are confronted to make ordering decisions for a large category of products offered to end consumers. In this paper, we extend the classical mono-product News-Vendor Problem to a multi-product News-Vendor Problem with demand transferring and demand substitution. We focus on the joint determination of optimal product assortment and optimal order quantities. Computational algorithms are presented to solve the problem. We compare the global optimization policy with some other policies used in practice by numerical examples.
\end{abstract}

\section{INTRODUCTION}

Product variety is a key element of competitive strategy. Many retailers become successful by offering a wide selection of products. Supermarkets such as Wal-Mart and Carrefour are good examples from grocery retailing. Demand for variety comes from both the taste of diversity for an individual consumer and diversity in tastes for different consumers. However, despite the advantages of product variety, the full degree of variety cannot be supplied generally, owning to the increase of cost in inventory, shipping, and merchandise presentation, etc. Thus, the optimization of product assortment (the products to sell), and the order quantity for each product, is a relevant decision that retailers face.

The News-Vendor Problem is a classical problem in inventory management aiming at finding the optimal order quantity which maximizes the expected profit under probabilistic demand [1], [2]. The demand for products is unknown, thus the order quantity for each product should be optimized due to the trade-off between two situations: if the order quantity is not enough, underage happens and lost sale causes lost profit; if the order quantity is too large, overstock happens. The classical mono-product News-Vendor Problem is in the situation that only one product is considered. In our case, we consider multiple products. Thus, to optimize the assortment, two other important factors should also be considered. First, product variety brings possible substitution when underage happens: different colors or styles, for example, act as substitutes when the client finds a product is out of stock. Second, beside of the purchasing cost which increases with the order quantity, other fixed costs are associated with stocking a product, e.g. the cost related to a fixed space for each product, the related labor cost, etc. In these situations, the fixed cost will clearly reduce the assortment size.

This paper extends the classical News-Vendor Problem to determine the product assortment and product order quantities considering product substitution. We develop a model for the demand transferring effect when some products are abandoned. We use the Monte Carlo method to solve the multi-product News-Vendor Problem under substitution. Analysis of illustrative examples shows that assortment optimization and substitution have significant effects on the optimal order quantities and on the expect profit. The rest of the paper is organized as follows. Section 2 presents the related literature review. In section 3, we formulate the News-Vendor Problem with multiproducts under demand substitution. In section 4 , we solve the joint optimization of assortment and optimal order quantities and give computational algorithms. In section 5, numerical examples are provided. Section 6 contains concluding remarks.

\section{LITERATURE REVIEW}

A survey of the literature on the News-Vendor Problem is provided by [1], [2]. Over the last decades, interest for multi-product News-Vendor Problem continues unabated. The special case where different products have independent demand and no possible substitution is considered by [3]. The topic of substitution in inventory management first appears in [4]. Papers on this topic can be divided into 3 categories according to their substitution types: papers of the first category deal with one-direction substitution or firm-driven substitution, where only higher grade product can substitute a lower grade product, because the supplier makes decisions for consumers on choosing substitutes (see, e.g., [5]-[9]). For example, the retailer provides a high quality product as a substitute for a consumer who prefers a product with lower quality but it is out of stock. The second category consists of papers where arriving consumers' number follows a stochastic function and consumers make purchasing decisions under probabilistic substitution when their preferred product is out of stock (see, e.g., [10] and [11]). Here the consumers come one by one and choose their substitutes within the remaining products by themselves. The third category consists of papers considering that each product can substitute for other products and the fraction that one out-of-stock product is substituted by another product is deterministic. Moreover, this category can be divided into subcategories as either the two-product (see [4], [12]-[15]) or multi-product case (see [16]-[19] and centralized or competitive case. [17] obtained optimality conditions for both competitive and centralized versions of the single period multi-product inventory problem with substitution. [20] study a multi-product competitive News-Vendor problem with shortage 
penalty cost and product substitution. They characterize the unique Nash equilibrium of the competitive model. An iterative algorithm is developed based on approximating the effective demand by a service-rate approximation approach.

Most of earlier works focus on optimizing order quantities for a given assortment of products. [10] and [21] deal with optimal assortment decision as well as optimal order quantity decision. [21] considers also the demand cannibalization of the standard product demand owning to retailing its customized extensions. The work of this paper differs from earlier research in many ways. Unlike [10] who model demand by a negative binomial process and [21] who model demand as a Poisson process, our method can be adapted to general demand distributions. We consider the transfer of demand owning to the abandonment of some products, while the demand of the abandoned products is totally lost in [10]. In addition, we do not approximate of the effective demand, while [10] who approximate the effective demand by a service-rate approximation approach. Furthermore, we develop heuristic solutions to solve the problem.

\section{PROBLEM MODELING}

The News-Vendor model is appropriate for seasonal product retailing problems where decisions should be made before the beginning of the selling season. In addition, the NewsVendor (NV) is often faced with a choice set of similar products (we call the set as a product category) with different colors, sizes, etc. Each product is associated with a market share $p_{i}$, which represent the percentage of a market defined in term of unit. Each product has a unit selling price, unit purchasing cost and in case of over-stock, the product is recycle with a salvage value. Considering a product category consists of $n$ substitutable products in the market, intuitively more products will bring more sale and thus the NV might realize more profit. But the fact of fixed cost $K_{i}$ related to each product will surely reduce assortment size. In these reasons, the NV might choose a product assortment denoted $M$ to stock for the selling season and other products (subclass $R$ ) will not be stocked. The demand transferring happens: the demand of not stocked product will partly be transferred to stocked products. When the selling season begins, customers will purchase the stocked products and when under-stock happens, they make substitutions. Before the selling season, the NV decides both the products to sell in the selling season and the purchase quantity for each product. The objective is to maximize the expected profit, subject to several constraints. The sequence of events is shown in figure 1 .

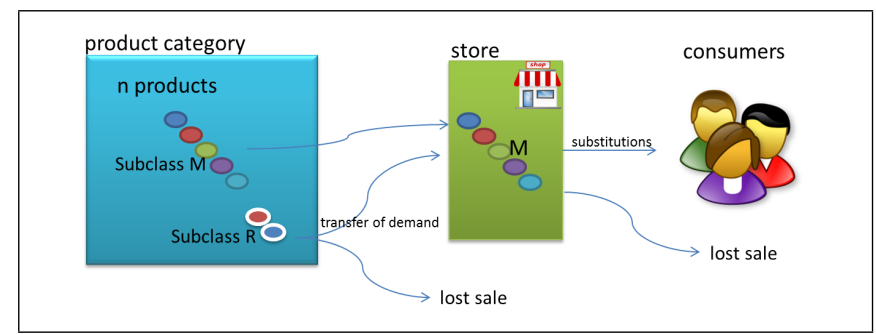

Fig. 1. Sequence of events

Define the following notations: $x \quad$ a random variable: total demand for the product category, with a continuous probability function $f(x)$ and cumulative function $F(x)$, who has a mean $\mu$ and standard deviation $\sigma$,

$X$ realized value of $x$,

$x_{i} \quad$ demand for products $i$, with a probability function $f_{i}\left(x_{i}\right)$ and cumulative function $F_{i}\left(x_{i}\right)$,

$X_{i} \quad$ realized value of $x_{i}$

$p_{i} \quad$ the market share proportion of demand for product $i$,

$L_{i} \quad$ the probability that a consumer who prefers product $i$ is unwilling to substitute,

$K_{i} \quad$ fixed cost related to displaying product $i$,

$v_{i} \quad$ unit selling price for product $i$,

$w_{i} \quad$ unit purchasing price cost product $i$,

$s_{i} \quad$ unit salvage price for product $i$,

$x_{m}^{\prime} \quad$ net demand for product $m$ after the transfer of demand, with a probability function $f_{m}^{\prime}\left(x_{m}^{\prime}\right)$ and cumulative function $F_{m}^{\prime}\left(x_{m}^{\prime}\right)$, who has a mean $\mu_{m}^{\prime}$ and standard deviation $\sigma_{m}^{\prime}$,

$X_{m}^{\prime} \quad$ net realized value of $x_{m}^{\prime}$,

$p_{m}^{\prime}$ the new market share proportion of demand for product $m$ after the transfer of demand, $m \in M$

$\alpha_{i j} \quad$ the fraction of consumers that purchase product $j$ as a substitute when product $i$ is out of stock, $i, j=$ $1,2,, m$,

Decision variables:

$M$ the subclass of products to be displayed,

$Q$ the vector of order quantities, $Q=\left[Q_{m}\right], m \in M$. Here $Q_{m}$ is the order quantity for product $m$.

The assumptions can be stated formally as follows:

ASSUMPTION 1: The total demand distribution for the product category is known.

ASSUMPTION 2: Given the realized total demand $X$, the initial realized demand $X_{i}$ equals to $p_{i} X$.

ASSUMPTION 3: A part of demand for abandoned subclass $R$ is lost (lost sale, the probability is represented by $\left.L_{i}\right)$. The other part of demand for abandoned subclass $R$ will be transferred to subclass $M$ in proportion to their original market shares.

ASSUMPTION 4: Consumers will purchase the products that will be stocked for the selling season, i.e. product in subclass $M$.

ASSUMPTION 5: If their first choice product is not available, consumers may choose to purchase a substitute product with the portion of substitution denoted as $\alpha_{i j}$. If this substitute product is out of stock, the consumer will leave (a lost sale), i.e. there is no second substitute attempt.

ASSUMPTION 6: A fixed cost is related to each product, if the $N V$ wants to stock it for the selling season.

\section{A. Transfer of demand modeling}

When product $r$ of subclass $R$ is abandoned, a percentage $L_{r}$ of demand is lost. Other demand is distributed to the products of subclass $M$. The additional demand transferred 
to product $m(m \in M)$ is:

$$
\frac{p_{m}}{\sum_{m} p_{m}} \sum_{r}\left[\left(1-L_{r}\right) X_{r}\right], r \in R, m \in M
$$

After the transfer of demand, the net realized demand $X_{m}^{\prime}$ for product $m$ is obtained as:

$p_{m} X+\frac{p_{m}}{\sum_{m} p_{m}} \sum_{r}\left[\left(1-L_{r}\right) X_{r}\right]=p_{m}\left(1+\frac{\sum_{r}\left[p_{r}\left(1-L_{r}\right)\right]}{\sum_{m} p_{m}}\right) X$

The new demand proportion $p_{m}^{\prime}$ for product $m$ is:

$$
p_{m}\left(1+\frac{\sum_{r}\left[p_{r}\left(1-L_{r}\right)\right]}{\sum_{m} p_{m}}\right)
$$

Property 1: The probability distribution for the net demand $x_{m}^{\prime}$ for product $m$ denoted as $f_{m}^{\prime}\left(x_{m}^{\prime}\right)$ follows:

$$
f_{m}^{\prime}\left(x_{m}^{\prime}\right)=\frac{f\left(\frac{x}{p_{m}^{\prime}}\right)}{p_{m}^{\prime}}
$$

1)

Proof: The proof is provided in the Appendix (c.f. annex

Other properties can then be derived from Property 1 .

Property 2: The cumulative distribution for the net demand $x_{m}^{\prime}$ for product $m$ denoted as $F_{m}^{\prime}\left(x_{m}^{\prime}\right)$ follows:

$$
F_{m}^{\prime}\left(x_{m}^{\prime}\right)=F\left(\frac{x}{p_{m}^{\prime}}\right)
$$

Property 3: The standard deviation of $x_{m}^{\prime}$ is :

$$
\sigma_{m}^{\prime}=p_{m}^{\prime} \sigma
$$

Property 4: The mean value of $x_{m}^{\prime}$ is:

$$
\mu_{m}^{\prime}=p_{m}^{\prime} \mu
$$

\section{PROBLEM FORMULATION}

The NV decides both which products to stock (the assortment) and the order quantity for each product. The objective of our method is to optimize the expected profit, with fixed cost $K_{i}$ associated with stocking product $i$. We use two policies to solve the problem: sequential optimization and global optimization. The first policy determines the optimal product assortment considering only the transfer of demand in the first step, then in the second step determines the optimal order quantities considering the substitutions within this assortment. The global optimization policy considers simultaneously the transfer of demand and substitution to determine the optimal assortment. While the global optimization policy gives a solution outperforming the first one, sequential optimization policy shows close results with less computation time.

\section{A. Sequential optimization}

Assortment decision $M^{*}$ : The sequential optimization policy determines the optimal assortment in the first step. We obtain the optimal subclass $M^{*}$ by considering only the transfer of demand. Then for a given product subclass $M$, the demand follows continuous probability functions $f_{m}^{\prime}, m \in M$. The profit for product $m$ can be easily developed, see equation 8.

$\pi_{m}= \begin{cases}v_{m} x_{m}-w_{m} Q_{m}+s_{m}\left(Q_{m}-x_{m}\right)-K_{m} & \text { if } x_{m}<Q_{m} \\ v_{m} Q_{m}-w_{m} Q_{m}-K_{m} & \text { otherwise }\end{cases}$

The total profit is the sum of the profits for each product and the second derivative of the expected profit function proves that it is concave with $Q_{m}, \forall m \in M$. The optimal order quantity $\widetilde{Q}_{m}$ for product $m$ respects:

$$
\begin{gathered}
f_{i}^{\prime}\left(\widetilde{Q}_{m}\right)=\frac{v_{m}-w_{m}}{v_{m}-s_{m}} \\
E(\pi(\widetilde{Q}))=\sum_{m \in M}\left[\int_{0}^{\widetilde{Q}_{m}}\left(v_{m}-s_{m}\right) x_{m} f_{m}^{\prime}\left(x_{m}\right) d x_{m}-K_{m}\right]
\end{gathered}
$$

We find same order quantity conditions as the classical NewsVendor problem because we consider no substitution effects in this step. The optimal expected profit is developed in equation 10. Enumeration of all possible $M$ gives $M^{*}$ that maximize the optimal expected profit without considering the substitution effect.

Considering the substitution to solve $Q^{*}$ : Once the NV decides the optimal product subclass $M^{*}$, it is a multi-product substitution problem similar to the one considered by [17]. As the selling period continues, stock-out will happen, a part of unsatisfied demand will be lost with the proportion $L_{i}$. The remaining demand will be shared by other products of $M^{*}$ in proportion to their market shares. The substitution fractions $\alpha_{i j}$ are developed as:

$$
\alpha_{i j}=\frac{p_{j}^{\prime}\left(1-L_{i}\right)}{\sum_{k \neq i} p_{k}^{\prime}}=\frac{p_{j}\left(1-L_{i}\right)}{\sum_{k \neq i} p_{k}}, i, j, k \in M^{*}
$$

Define $x_{i}^{s}$ as the effective demand for product $i$, which is the sum of the net demand $x_{i}^{\prime}$ and the additional demand for product $i$ received from other out-of-stock products caused by substitution. We have

$$
x_{i}^{s}=x_{i}+\sum_{j \neq i} \alpha_{j i}\left(x_{j}-Q_{j}\right)^{+}
$$

Here $x^{+}=\max (0, x)$. The profit for a product is the revenue subtracting the overage cost, the underage cost and the fixed cost. Then the expected profit function is:

$$
\begin{array}{r}
E(\pi(Q))=E \sum_{i}\left[\left(v_{i}-w_{i}\right) x_{i}^{s}-\left(v_{i}-w_{i}\right)\left(x_{i}^{s}-Q_{i}\right)^{+}\right. \\
\left.-\left(w_{i}-s_{i}\right)\left(Q_{i}-x_{i}^{s}\right)^{+}-K_{i}\right]
\end{array}
$$


The first-order necessary optimality conditions are derived from equation 13 as follows:

$$
\begin{aligned}
& \operatorname{Pr}\left(x_{i}<Q_{i}^{*}\right)-\operatorname{Pr}\left(x_{i}<Q_{i}^{*}<x_{i}^{s}\right) \\
& \quad+\sum_{j \neq i} \frac{v_{j}-s_{j}}{v_{i}-s_{i}} \alpha_{i j} \operatorname{Pr}\left(x_{j}^{s}<Q_{j}^{*}, x_{i}>Q_{i}^{*}\right) \\
& \quad=\frac{v_{i}-w_{i}}{v_{i}-s_{i}}
\end{aligned}
$$

$Q_{i}^{*}$ denotes the optimal order quantity for product $i$ in subclass $M^{*}$. The second and third term in equation 14 equal to zero for the special case where no substitution is considered, then equation 14 becomes the order quantity optimality condition for a classical News-Vendor problem (equation 9). Let's note that equation 14 is the same as the solution of Serguei and Nils [17]. Thus, for a fixed product subclass $M^{*}$, the fixed cost has no effect on the optimal order quantities.

\section{B. Global optimization}

For a subclass $M$, if we consider the substitution effect, the optimal expected profit will be different from equation 10. Thus, the subclass $M^{*}$ determined by the sequential optimization policy can be not optimal. To obtain the optimal subclass, we need to consider simultaneously the demand transfer and substitution effects.

Given a product subclass $M$, the net demand $x^{\prime}$ and the effective demand $x_{i}^{s}$ are derived in equation 4 and 12. The expected profit and the optimal order quantities have same equations as equation 13 and 14. The difference is that the subclass $M$ is no longer given, but to be determined. There are $2^{n}$ possibilities for $M$, enumerate all of them and we can find $M^{*}$ who maximizes of the expected profit.

\section{Policies used in practice}

We propose 3 decision policies that can be used in practice and compare them with the sequential optimization (Policy 4) and global optimization (Policy 5) policies. Our goals in examining these policies are: 1. to understand qualitatively any distortions that might be introduced in inventory decisions if one ignores (or approximates) substitution effects, 2. to understand any distortions that might be introduced if one considers the assortment and substitution effects separately, and 3. to gauge the impact of substitution effects on assortment and profits.

Policy 1: NV with $n$ initial products, no product abandonment nor substitution. It makes the assumption that substitution effects are ignored entirely. Thus there is neither demand transferring nor substitution. The total expected profit is developed in the same way as equation 10. We have:

$$
\begin{aligned}
E(\pi(Q))= & \sum_{i=1}^{n}\left[\int _ { 0 } ^ { Q _ { i } } \left(x_{i}\left(v_{i}-w_{i}\right)\right.\right. \\
& \left.\quad-\left(Q_{i}-x_{i}\right)\left(w_{i}-s_{i}\right)\right) f_{i}\left(x_{i}\right) d x \\
& \left.+\int_{Q_{i}}^{\inf } Q_{i}\left(v_{i}-w_{i}\right) f_{i}\left(x_{i}\right) d x_{i}-K_{i}\right]
\end{aligned}
$$

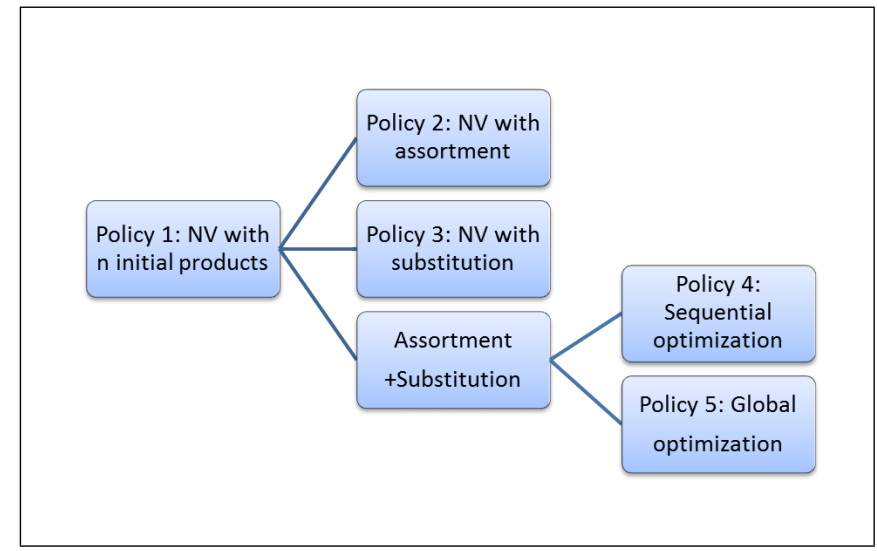

Fig. 2. Decision policies

The optimal order quantity for product $i$ is:

$$
Q_{i}^{*}=p_{i} F^{-1}\left(\frac{v_{i}-w_{i}}{v_{i}-s_{i}}\right)
$$

Then the optimal expected profit is derived as:

$$
E\left(\pi\left(Q^{*}\right)\right)=\sum_{i=1}^{n}\left[\int_{0}^{Q_{i}^{*}} x_{i}\left(v_{i}-s_{i}\right) f_{i}\left(x_{i}\right) d x-K_{i}\right]
$$

Policy 2: NV with assortment, the News-Vendor considers only the transferring of demand. For a given product subclass $M$, the demand probability functions are changed from $f_{m}$ to $g_{m}, m \in M$. The optimal expected profit is obtained by equation 10 and the optimal order quantities by equation 9. Enumeration of all possible $M$ gives $M^{*}$ that maximize the optimal expected profit.

Policy 3: NV with substitution, the News-Vendor Problem for $n$ products considering the substitution. We have same optimal order quantities as equation 4 with $M^{*}$ identical to the product category and the optimal expected profit function is:

$$
\begin{array}{r}
E(\pi(Q))=E \sum_{i}^{n}\left[\left(v_{i}-w_{i}\right) x_{i}^{s}-\left(v_{i}-w_{i}\right)\left(x_{i}^{s}-Q_{i}\right)^{+}\right. \\
\left.-\left(w_{i}-s_{i}\right)\left(Q_{i}-x_{i}^{s}\right)^{+}-K_{i}\right]
\end{array}
$$

Policy 4: Sequential optimization, the News-vendor considers sequentially the transferring of demand and the substitution. We get the value of $M^{*}$ obtained by policy 2 then consider the substitution effect to get the optimal order quantities and expected profit.

Policy 5: Global optimization, the News-Vendor Problem considers simultaneously the demand transfer and substitution effects. See more details in section 4.B.

\section{Algorithm}

Caused by the complexity of equation 14 , we cannot get the optimal order quantities directly. Thus we use a Random-walk method to find the solution. The procedure is as follows: 
Step 1: Initialize $Q$ with the values obtained by the optimal order quantity condition of $M$ independent classic NewsVendor Problems; initialize the walk length $\lambda$ and the limit of it: $\epsilon$.

Step 2: generate $n$ random points around $Q$ with a distance $\lambda$ to $Q$. And get the best point $Q^{\prime}$ among these $n$ points;

Step 3: if $Q^{\prime}$ is better than $Q$, assign the value of $Q^{\prime}$ to $Q$, go to step 2 . If not, halve the value of $\lambda$, if $\lambda>\epsilon$, go to step 2, otherwise, go to step 4;

Step 4: if $Q^{\prime}$ satisfies the optimality condition, stop, otherwise go to step 1.

We use two methods to determine in step 3 that $Q^{\prime}$ is better than $Q$ or not. Both of these methods are carried out by Monte Carlo method.

First, we define an objective function as the difference between the left side and right side of equation 14 . If the order quantities are optimal, equation 14 should be satisfied, thus the objective equation should be equal to zero. But in fact, zero can not be strictly realized in computation. So we regard $Q$ is better than $Q$ if $h\left(Q^{\prime}\right)<h(Q)$ and the optimality condition is obtained when $h\left(Q^{\prime}\right)<0.1$; Second, we regard $Q^{\prime}$ is better than $Q$ if $Q^{\prime}$ brings a better expected profit than $Q$. The value of expected profit is obtained from equation 18 .

\section{NUMERICAL ANALYSIS}

We use normally distributed demand in our example, other demand distributions will also work. We consider a product category of 6 products with mean total demand $\mu=100$, the selling price, purchasing cost, salvage value, fixed cost and unwilling-to-substitute fraction are the same for all products: $v=9, w=6, s=3, K_{i}=K$, and $L_{i}=L$. The market shares are set as an approximate linear increase: $p_{i}=(0.09,0.12,0.15,0.18,0.21,0.25)$. These simplifications facilitate the comparison with other heuristic policies and make it easier to see how different performances vary with the market shares. We use the Monte Carlo method to compute the optimal order quantities and expected profits. In this example, we use the default random generator in Matlab generating 10000 samples to represent the demand with normal distribution (at about a confidence level of $98 \%$ with a sampling relative error $2.3 \%$ ).

Considering $K=15$ and $L=0.5$, the profit comparison for the five policies is given in figure 3 . The results show that the global optimization policy outperforms other policies and the sequential optimization does very well particularly, achieving $100 \%, 100 \%, 99.9 \%, 100 \%$ and $100 \%$ of the profits generated by the global optimization policy, respectively, at $\sigma=10,20,25,30$ and 40. Intuitively the expected profit decreases with $\sigma$ for every policy we use. Considering the assortment, the total order quantity is remarkably reduced comparing with the Independent News-Vendor policy, see figure 4. Order quantities for each product obtained by different policies with $\sigma=30$ are shown in figure 5 . We find that the order quantity increases with the market share value for each policy. Similar results are found with other values of $\sigma$. As shown in table I, the value of assortment size is reduced comparing with the Independent News-Vendor policy in using the sequential optimization or global optimization policy.

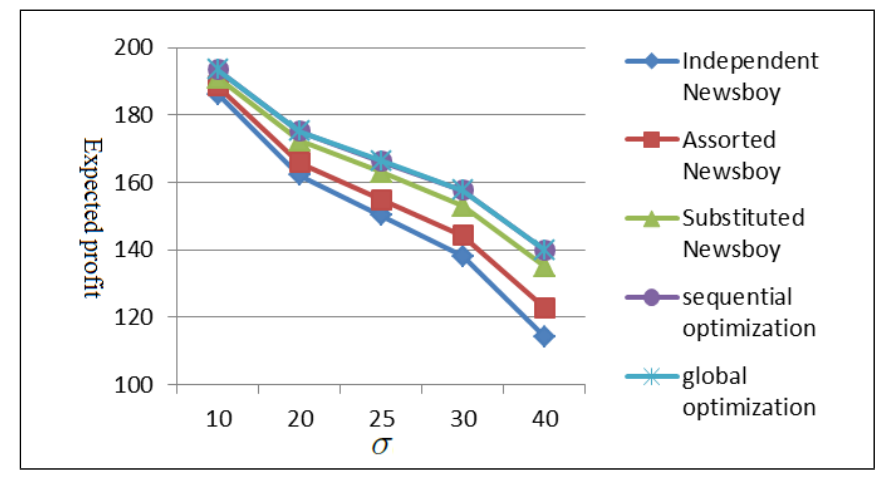

Fig. 3. Expected profit for different policies with $\sigma=10,20,25,30,40$.

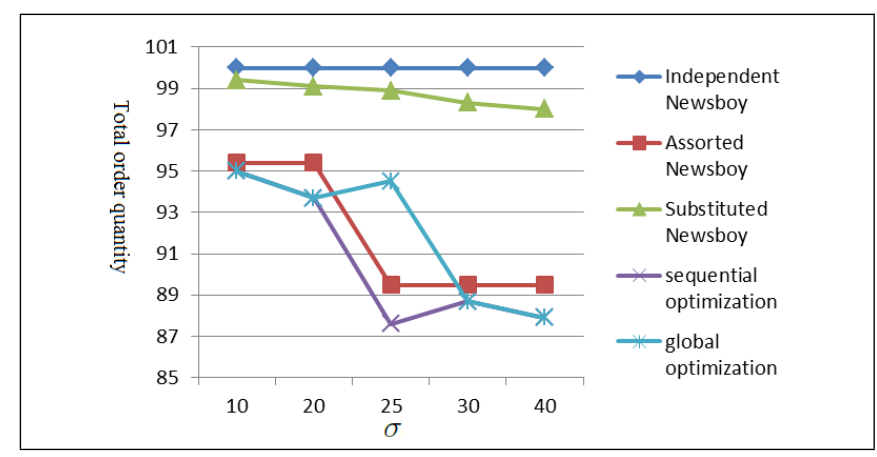

Fig. 4. Total order quantity for different policies with $\sigma=10,20,25,30,40$.

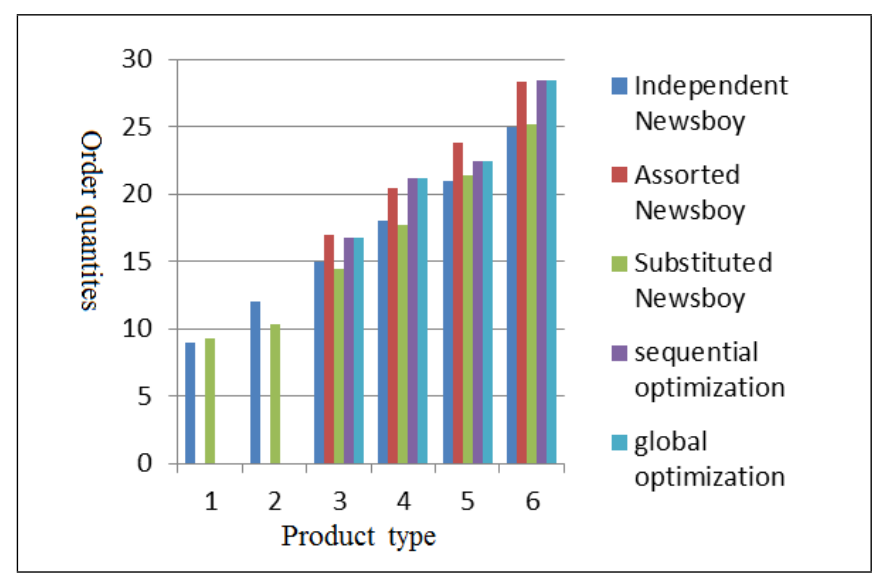

Fig. 5. Order quantities for $\sigma=30, \mathrm{~K}=15, \mathrm{~L}=0.5$

\begin{tabular}{c|c|c|c|c|c|}
\hline & $\sigma=10$ & $\sigma=20$ & $\sigma=25$ & $\sigma=30$ & $\sigma=40$ \\
\hline \hline Independent News-Vendor & 6 & 6 & 6 & 6 & 6 \\
Assorted News-Vendor & 5 & 5 & 4 & 4 & 4 \\
Substituted News-Vendor & 6 & 6 & 6 & 6 & 6 \\
Sequential Optimization & 5 & 5 & 4 & 4 & 4 \\
Global Optimization & 5 & 5 & 5 & 4 & 4 \\
\hline
\end{tabular}

TABLE I. THE ASSORTMENT SIZE FOR DIFFERENT POLICIES WITH $\sigma=10,20,25,30,40$

Comparing policy 1 with policy 2 and 3: If we fix the value of $\sigma$, the optimal order quantities for each product can be determined, and these quantities do not change with $K$ or $L$. While the expected profit is the smallest, the total order quantity obtained by policy 1 is the largest compared with policy 2 and 3 .

Considering the assortment or substitution both increase 
the profit in our examples. As the assortment size decreases, the total fixed cost decrease, thus the profit could increase. The substitution improves the profit in two aspects: on one hand, the unit underage cost is lower because the unsatisfied demand for one product may be substituted by another product; on the other hand, the unit overage cost for a product is lower too, because it receives some additional substitute demand from other products.

Policy 2 and 3 both decrease the total order quantity. When the assortment is considered, some product could be abandoned and some demand is lost, thus the total order quantity should be less than that of the News-Vendor Problem with $n$ initial products. When substitution is considered, the underage cost is reduced, which creates the intensive to decrease the order quantity; and overage cost is also reduced, which creates the opposite effect: to increase the order quantity. In our examples the first effect dominates. In fact, we can find that the lost sale related to the substitution caused by an underage is smaller than that caused by an overage. Thus, the substitution has more important effect on underage rather than overage.

Moreover, the abandonment begins with the product with the smallest market share. As the value of $\sigma$ increases more products will be abandoned. The intuition to these results is the following: firstly, the stocking cost $K_{i}$ leads to abandon the less popular products because the cost of these products is bigger than the revenue. As the uncertainty increases, the revenue decreases, and then more products become unprofitable. Secondly, popular products can bring more profit. They have larger demand, thus more demand will be lost when they are abandoned, while abandoning less popular products will lose less demand.

Comparing policy 4 with policy 2 and 3: The sequential optimization policy brings more profit compared with these two models. The difference of the expected profit between the sequential optimization policy and Substituted News-Vendor policy can be more obvious when we change the parameters, e.g. let $K=25$. The combination of assortment and substitution seems to significantly improve the profit.

The total order quantity obtained by the sequential optimization policy is smaller than that of policy 2 and 3 . This is intuitive because the News-Vendor with assortment obtains less total order quantity than News-Vendor with substitution and further reduction is made if we consider the substitution effect consecutively after the assortment.

Comparing policy 5 with policy 4: In our examples, global optimization policy obtains same results as the sequential optimization policy, but the case $\sigma=25$. In this case, the assortment size is bigger than that obtained by sequential optimization policy, the order quantities for each product are not the same either, and the profit is smaller but very close. We try different combinations of parameters $(K, L, \sigma)$, and get same results: the assortment size and total profit are not smaller but close to that obtained by sequential optimization policy.

The substitution makes it possible to expand the assortment size, because while one product is not profitable in Assorted News-Vendor policy, the substitution can make it receive some additional substitute demand from other products, thus this product can be profitable and not abandoned.

\section{A. Impact of $L$}

This example shows the performance under different value of unwilling-to-substitute fraction $L$. Considering $\sigma=10,25$, 40 , the profit, assortment size and total order quantity are calculated by the global optimization policy.

For a fixed $\sigma$, the assortment size increases with $L$ and the expected profit decreases. For a fixed value of $L$, the expected profit decreases with $\sigma$; the assortment size for $\sigma=10$ is equal to or larger than others but the special cases $L=1,0.1$; the total order quantity increases with $\sigma$ when $L=1$, while in other cases, we have no clear rules. But we can find that in our case, the total order quantity is smallest for $L=0.3$ and reaches maximum when $L=1$ or $L=0$.

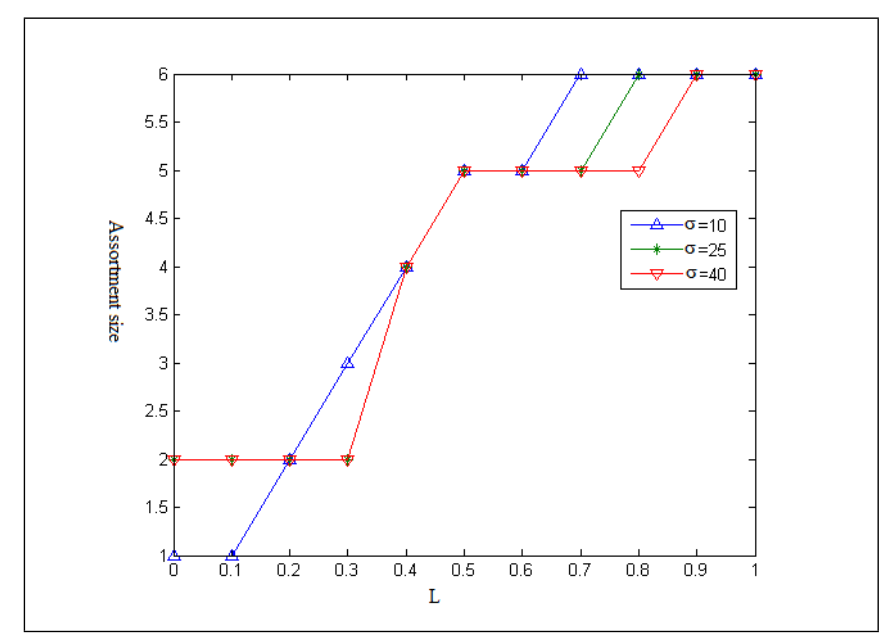

Fig. 6. the assortment size as a function of $\mathrm{L}$, for $\sigma=10,25,40$

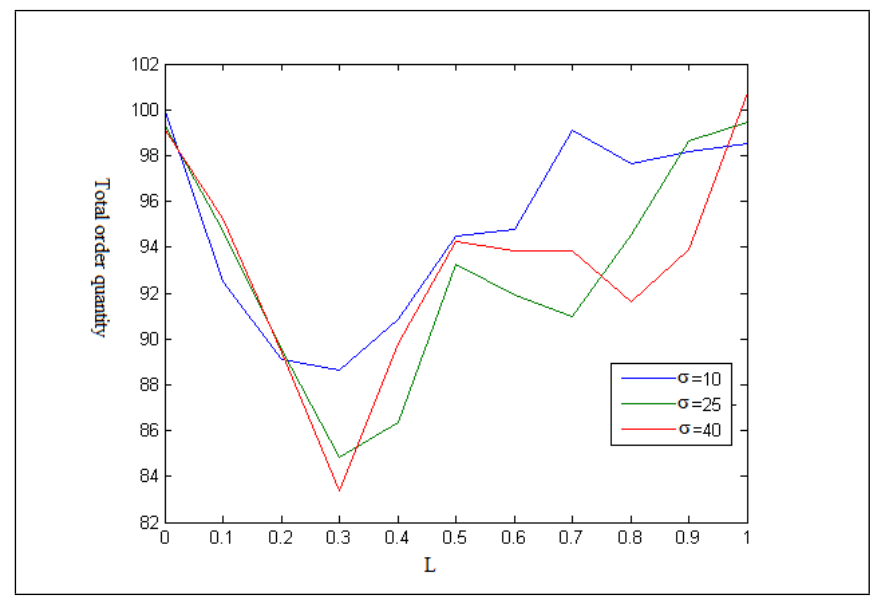

Fig. 7. the total order quantity as a function of $\mathrm{L}$, for $\sigma=10,25,40$

Intuitions to these results are the following: The increase of $L$ results in more lost sale in two aspects: when one product is abandoned on one hand and when one product in stock comes to an underage on the other hand. The first one leads to a bigger assortment size, and the second one reduces the expected profit. Intuitively the expected profit decreases with $\sigma$ for a normally distributed demand. For a fixed $L$, we know that a larger assortment size reduces the lost sale but brings more stocking cost, so its a trade-off to determine the size. When $\sigma$ is smaller, the profit coming from reducing the lost sale is bigger, 


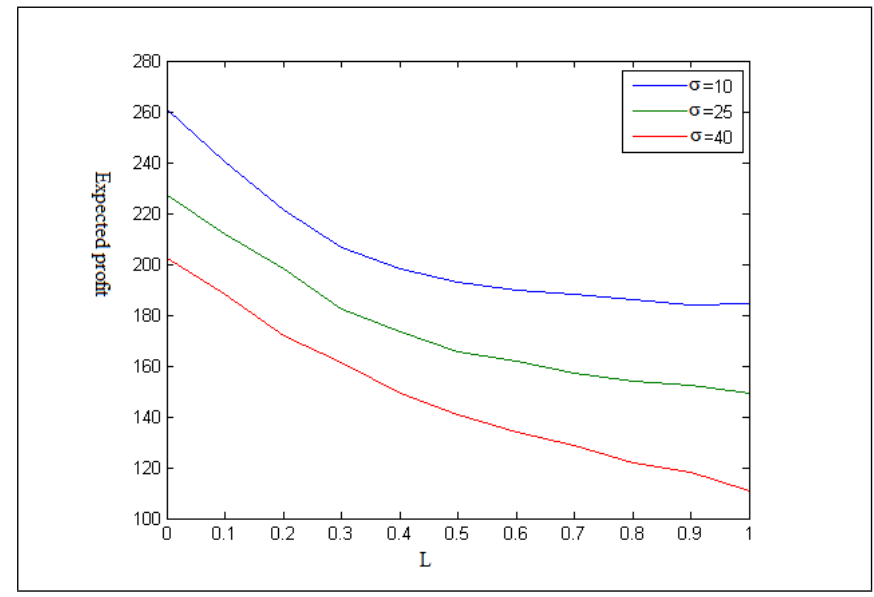

Fig. 8. the expected profit as a function of $\mathrm{L}$, for $\sigma=10,25,40$

so the trade-off tends to bigger assortment size. Special case is when $L=0$ and 0.1 , the assortment size for $\sigma=10$ is 1 , this means there is no alternate product to choose when the product is at underage. The reason is: when $L$ and $\sigma$ are both small, e.g. $L=0,0.1, \sigma=10$, the demand substitution benefit is less than the stocking cost of an additional product. The total order quantity does not respect clear rules for different $\sigma$, because the quantity depends on the assortment size (not the same for different $\sigma$ ). In the special case when $L=1$, each of them have 6 products in the assortment, and there is no transfer of demand nor substitution, thus same as a classic News-Vendor Problem. The reason why the order quantity reaches maximums for $L=$ 0 and $L=1$ is that, the lost sale is zero when $L=0$ and very small when $L=1$ (no abandoned product).

\section{B. Impact of $K$}

This example shows the performance under different value of stocking cost. We consider $L=0.5$. The profit and the assortment size are calculated by the global optimization policy with $\sigma=10,25,40$, see figure 9,10 .

For a fixed $\sigma$, the assortment size decreases with $K$ with the same $\sigma$ and decreases with $\sigma$ for same value of $K$. As we discussed before, the trade-off between lost sale and stocking cost determine the assortment size. When $K$ is larger, the stocking cost has more important influence and when $\sigma$ is bigger, the influence of lost sale is less important, thus both leading a smaller stocking size. Intuitively the expected profit decreases with $\sigma$ and $K$.

\section{CONCLUSION}

This paper extends the classical News-Vendor Problem to solve the joint optimization of the product assortment and the order quantities considering the demand transferring effect and the substitution effect within the assortment.

We developed the transferring fractions and substitution fractions in proportion to the market shares. The randomwalk Monte Carlo method provides an efficient computational approach to get the value of expected profit and optimal order quantities for a product assortment. An enumeration of all possible product assortments is done to search the best one.

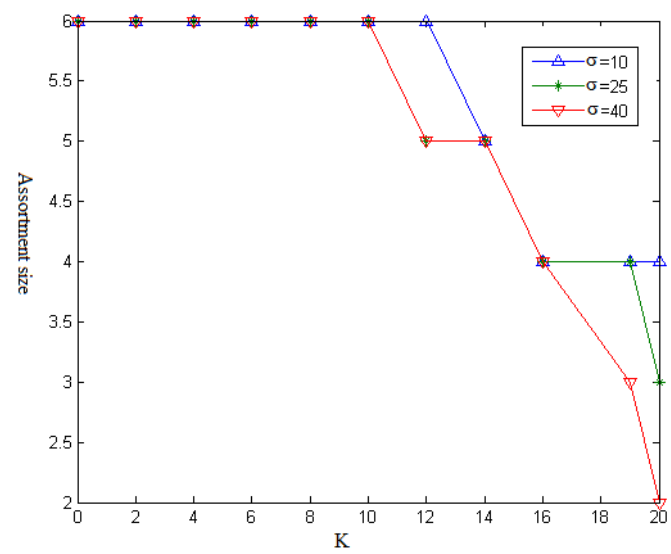

Fig. 9. the assortment size as a function of $\mathrm{K}$, for $\sigma=10,25,40$

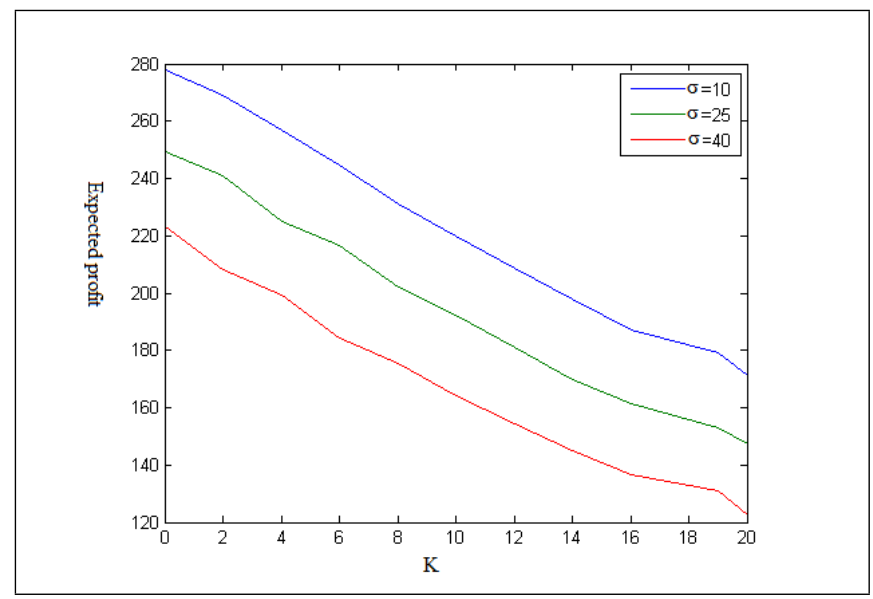

Fig. 10. the expected profit as a function of $\mathrm{K}$, for $\sigma=10,25,40$

The numerical examples show insights regarding the performances of the News-Vendor Problem. Our examples indicate that the demand transferring and substitution have remarkable effects on the assortment, expected profit, and optimal order quantities. And the sequential optimization policy and global optimization policy both bring better profit performance than separately. Global optimization obtains the best profit, but the sequential optimization policy shows close results and the computing time is considerably reduced.

With the global optimization policy, several results can be derived from numerical results: The expected profit decreases with the fixed cost value, the fraction of lost sale and demand uncertainty. Assortment size increases with the fraction of lost sale but decrease with the fixed cost value. The total order quantity does not respect strict behaviors but it shows that the order quantity reaches the maximums when lost sale fraction is zero or $100 \%$, and tends to decrease with fixed cost value.

\section{APPENDIX}

Annex 1: $X_{m}^{\prime}=P_{m} X$, thus the probability that $X \in(a, b)$ equals to the probability that $X_{m}^{\prime} \in\left(P_{m} a, P_{m} b\right)$, regardless 
the value of $a$ and $b$ :

$$
\begin{aligned}
\int_{a P_{m}}^{b P_{m}} g_{m}(t) d t & =\int_{a}^{b} f(t) d t \\
& =\int_{a P_{m}}^{b P_{m}} \frac{f(t)}{P_{m}} d\left(P_{m} t\right) \\
& =\int_{a P_{m}}^{b P_{m}} \frac{f\left(\frac{t^{\prime}}{P_{m}}\right)}{P_{m}} d t^{\prime}
\end{aligned}
$$

This equation should be available for any value of $a$ and $b$, thus we have equation 4 .

\section{REFERENCES}

[1] M. Khouja, "The single-period (news-vendor) problem: literature review and suggestions for future research," Omega, vol. 27, no. 5, pp. 537 - 553, 1999. [Online]. Available: http://www.sciencedirect.com/science/article/pii/S0305048399000171

[2] Y. Qin, R. Wang, and A. J.Vakharia, "The newsvendor problem: Review and directions for future research," European Journal of Operational Research, vol. 213, pp. 361-374, 2011.

[3] H.-S. Lau and A. H.-L. Lau, "The multi-product multiconstraint newsboy problem: Applications, formulation and solution," Journal of Operations Management, vol. 13, no. 2, pp. 153 - 162, 1995. [Online]. Available: http://www.sciencedirect.com/science/article/pii/0272696395000190

[4] A. R. McGillivray and E. Silver, "Some concepts for inventory control under substitutable demand," Infor, vol. 16, no. 1, pp. 47-63, 1978.

[5] G. R. Bitran and S. Dasu, "Ordering policies in an environment of stochastic yields and substitutable demands," Operations Research, vol. 40, no. 5, pp. 999-1017, 1992. [Online]. Available: http://dx.doi.org/10.1287/opre.40.5.999

[6] Y. Bassok, R. Anupindi, and R. Akella, "Single-period multiproduct inventory models with substitution," Operations Research, vol. 47, no. 4, pp. 632-642, 1999. [Online]. Available: http://pubsonline.informs.org/doi/abs/10.1287/opre.47.4.632

[7] A. Hsu and Y. Bassok, "Random yield and random demand in a production system with downward substitution," Operations Research, vol. 47, no. 2, pp. 277-290, 1999. [Online]. Available: http://pubsonline.informs.org/doi/abs/10.1287/opre.47.2.277

[8] P. Dutta and D. Chakraborty, "Incorporating one-way substitution policy into the newsboy problem with imprecise customer demand," European Journal of Operational Research, vol. 200, no. 1, pp. 99 - 110, 2010. [Online]. Available: http://www.sciencedirect.com/science/article/pii/S0377221708010497

[9] U. S. RAO, J. M. SWAMINATHAN, and J. ZHANG, "Multi-product inventory planning with downward substitution, stochastic demand and setup costs," IIE Transactions, vol. 36, no. 1, pp. 59-71, 2004. [Online]. Available: http://dx.doi.org/10.1080/07408170490247304

[10] S. A. Smith and N. Agrawal, "Management of multi-item retail inventory systems with demand substitution," Operations Research, vol. 48, no. 1, pp. 50-64, 2000. [Online]. Available: http://pubsonline.informs.org/doi/abs/10.1287/opre.48.1.50.12443

[11] S. Mahajan and G. van Ryzin, "Inventory competition under dynamic consumer choice," Operations Research, vol. 49, no. 5, pp. 646-657, 2001. [Online]. Available: http://dx.doi.org/10.1287/opre.49.5.646.10603

[12] M. Parlar and S. Goyal, "Optimal ordering decisions for two substitutable products with stochastic demands," Opsearch, vol. 21, no. 1, pp. 1-15, 1984.

[13] B. A. Pasternack and Z. Drezner, "Optimal inventory policies for substitutable commodities with stochastic demand," Naval Research Logistics (NRL), vol. 38, no. 2, pp. 221-240, 1991. [Online]. Available: http://dx.doi.org/10.1002/1520-6750(199104)38:2¡221::AIDNAV3220380208;3.0.CO;2-7
[14] M. Khouja, A. Mehrez, and G. Rabinowitz, "A two-item newsboy problem with substitutability," International Journal of Production Economics, vol. 44, no. 3, pp. 267 - 275, 1996. [Online]. Available: http://www.sciencedirect.com/science/article/pii/092552739680002V

[15] M. Nagarajan and S. Rajagopalan, "Inventory models for substitutable products: Optimal policies and heuristics," Management Science, vol. 54, no. 8, pp. 1453-1466, 2008. [Online]. Available: http://pubsonline.informs.org/doi/abs/10.1287/mnsc.1080.0871

[16] S. A. Lippman and K. F. McCardle, "The competitive newsboy," Operations Research, vol. 45, no. 1, pp. 54-65, 1997. [Online]. Available: http://dx.doi.org/10.1287/opre.45.1.54

[17] S. Netessine and N. Rudi, "Centralized and competitive inventory models with demand substitution," Operations Research, vol. 51, no. 2, pp. 329-335, 2003. [Online]. Available: http://pubsonline.informs.org/doi/abs/10.1287/opre.51.2.329.12788

[18] K. Rajaram and C. S. Tang, "The impact of product substitution on retail merchandising," European Journal of Operational Research, vol. 135, no. 3, pp. 582 - 601, 2001. [Online]. Available: http://www.sciencedirect.com/science/article/pii/S0377221701000212

[19] X. Zhao and D. R. Atkins, "Newsvendors under simultaneous price and inventory competition," Manufacturing and Service Operations Management, vol. 10, no. 3, pp. 539-546, 2008. [Online]. Available: http://pubsonline.informs.org/doi/abs/10.1287/msom.1070.0186

[20] D. Huang, H. Zhou, and Q.-H. Zhao, "A competitive multiple-product newsboy problem with partial product substitution," Omega, vol. 39, no. 3, pp. 302-312, 2011

[21] J. Shah and B. Avittathur, "The retailer multi-item inventory problem with demand cannibalization and substitution," International journal of production economics, vol. 106, no. 1, pp. 104-114, 2007. 